\title{
Energy Metabolism in the Bone is Associated with Histomorphometric Changes in Rats with Hyperthyroidism
}

\author{
Zhuoqing Hu, Minqun Du ${ }^{\mathrm{a}} \quad$ Wenxiu Lai ${ }^{\mathrm{a}}$ Yanlong Liang ${ }^{\mathrm{a}}$ Qin Liu ${ }^{\mathrm{b}}$ Yilin $\mathrm{Mo}^{\mathrm{a}}$ \\ Jiaxin Bei ${ }^{a}$ Shuhui $\mathrm{Li}^{\mathrm{a}}$ Yajun Yang ${ }^{\mathrm{a}}$ Jinrong Xuc $\mathrm{Liao} \mathrm{Cui}^{\mathrm{a}}$ \\ ${ }^{a}$ Department of Pharmacology, Guangdong Key Laboratory for Research and Development of Natural \\ Drugs, Guangdong Medical University, Zhanjiang, 'bepartment of Endocrinology, Affiliated Hospital \\ of Guangdong Medical University, Zhanjiang, 'Department of Cardiovascular Internal Medicine, The \\ Second Affiliated Hospital of Guangdong Medical University, Zhanjiang, China
}

\section{Key Words}

Proteomics $・$ Rats $\cdot$ Hyperthyroidism $・$ Energy metabolism

\begin{abstract}
Background/Aims: In this study we assessed histomorphometric changes induced by thyroxine (T4) in 3-month-old hyperthyroid male rats and examined whether the potential mechanism of these changes is related to bone changes. Methods: Rats were classified as either hyperthyroid following administration of $250 \mu \mathrm{g} / \mathrm{kg} /$ day freshly prepared T4 by gavage for 2 months or euthyroid following administration of vehicle alone ( $n=8$ per group). We measured bone mineral density (BMD), bone biomechanical properties, and bone histomorphometric changes. Levels of serum indicators were also measured, and three right femurs from the two groups were selected for proteomic investigation. Results: Compared with the control rats, hyperthyroid rats showed a reduction in the fifth lumbar vertebral BMD as well as in the entire femoral BMD ( $p=0.033$ and 0.026 , respectively). Histomorphometric analysis of the proximal tibial metaphysis showed that the percentage of the trabecular area, trabecular number, and percentage of the cortical bone area in the hyperthyroid rats significantly decreased compared with those of the control rats. Conversely, bone formation rate (per unit of bone surface and bone volume), percentage of the osteoclast perimeter, trabecular separation, and endosteal mineral apposition rate in the hyperthyroid rats significantly increased compared with the control rats (all $p<0.05)$. Except for stiffness $(p=0.24)$, all bone biomechanical properties of the femur showed a significant decreasing trend in the hyperthyroid rats versus the control rats (all $p<0.05$ ). Serum levels of osteocalcin, alkaline phosphatase, terminal telopeptides of type $\beta$ collagen, and tartrate-resistant acid phosphatase were higher in the hyperthyroid rats than in the control rats (all $p<0.05$ ). Using isobaric tags for relative and absolute quantification (iTRAQ), the expression levels of 1,310 proteins were found to be significantly different between the hyperthyroid and control rats (711 proteins were upregulated and 599 were

Z. Hu, M. Du and W. Lai contributed equally to this work.
\end{abstract}

Liao Cui

and Jinrong $\mathrm{Xu}$

KARGER
Department of Pharmacology, Guangdong Key Laboratory for Research and

Development of Natural Drugs, Department of Cardiovascular Internal Medicine,

Guangdong Medical University (China); E-Mail cuiliao@163.com, zjeyxj@@163.com 


\section{Cellular Physiology Cell Physiol Biochem 2018;46:1471-1482

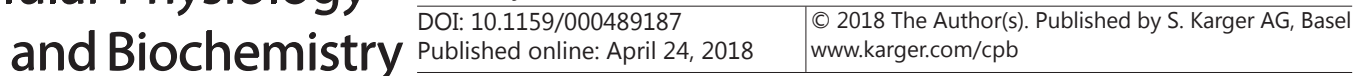

Hu et al.: Bone Energy Metabolism and Histomorphometric Changes in Hyperthyroid

Rats

downregulated in hyperthyroid rats). Gene Ontology and Kyoto Encyclopedia of Genes and Genomes pathway enrichment analyses showed that most of the enzymes in the glycolysistricarboxylic acid (TCA) cycle-oxidative phosphorylation signalling pathway were upregulated in hyperthyroid rats, and seven differentially expressed proteins were selected to verify the iTRAQ results using western blotting. Conclusion: Energy metabolism via the glycolysisTCA cycle-oxidative phosphorylation pathway is positively associated with T4-induced bone histomorphometric changes in rats.

(C) 2018 The Author(s)

Published by S. Karger AG, Basel

\section{Introduction}

Hyperthyroidism is a common cause of secondary osteoporosis. A clinical case-control study has shown that hyperthyroidism can cause net bone loss, decreased bone mineral density (BMD), and osteoporosis and increase the risk for fractures [1]. Both animal and clinical studies have shown that subjects with hyperthyroidism had higher bone resorption rates and bone formation marker levels [2-4] and that excessive levels of thyroid hormones might stimulate both osteoblast and osteoclast differentiation, however, the latter was more predominantly observed $[5,6]$. Hyperthyroidism led to a higher frequency of bone remodelling. In relation to this, we had found that thyroid hormones affect bone cells, are essential for normal bone remodelling, and play an important role in maintaining optimum bone matrix mineralization and bone mass, however the mechanisms of excess thyroxine (T4)-induced bone histomorphometric changes in adulthood are poorly understood.

Both T4 and 3, 3',5-triiodo-L-thyronine (T3) are vital thyroid hormones that cause accelerated rates of oxygen consumption and heat production in various body tissues [7]. Multiple metabolizing enzymes involved in glucose, fat, and protein metabolism were also found to be stimulated by the thyroid hormones; however, whether excessive levels of thyroid hormones can alter the metabolic enzymes in the bone is currently not known. With the development of proteomics in recent years, the molecular mechanisms of osteoblast and osteoclast biology have been identified through several proteomic analyses, and the key proteins involved in different molecular mechanisms were found to be different from those associated with various physiological stages of osteoblast and osteoclast biology. Nevertheless, the underlying histological consequence of hyperthyroidism remains to be elucidated by bone proteomic analysis. In this study, we assessed the histomorphometric changes in hyperthyroid male rats after T4 administration and investigated whether the potential mechanism involved is related to the bone changes using isobaric tags for relative and absolute quantification (iTRAQ).

\section{Materials and Methods}

\section{Measurement of bone and blood serum levels}

Twelve-week-old male rats were divided into two groups: hyperthyroid rats received $25 \mu \mathrm{g} / \mathrm{kg}$ freshly prepared T4 (Merck KGaA, Germany) and euthyroid control rats received vehicle alone ( $\mathrm{n}=8$ per group). All rats were fed a standard diet and had ad libitum access to food and drinking water. All rats also received subcutaneous injections of calcein on days 3,4,13, and 14 before being euthanized at the end of the experiment by cardiac puncture following anaesthesia with intraperitoneal injection of 3\% pentobarbital. Blood was collected for biochemical assessment of thyroid function and bone turnover at the Southern Medical University Huayin Laboratory, China. Further, the proximal tibial metaphysis secondary spongiosa (PTM), tibial shaft (TS), tibial shaft cross-sections, and fifth lumbar were collected for histomorphometric analysis using software for multimedia pathological imaging. The right femur was used for assessing BMD using the Hologic Discovery Dual X-Ray Absorptiometry scanner and for detecting the biomechanical quality of the diaphysis using the LIoyd LQ5K Plus material testing device.

The right PTM and right TS were harvested, and the medullary cavities were exposed using an IsoMet low-speed saw (Buehler, Lake Bluff, IL). specimens were then fixed in 10\% buffered formalin for 24 h, followed by dehydration in grade series of alcohol, defatting in xylene, and undecalcification via embedding in methyl methacrylate. The anterior PTM spongiosa was cut into 8- and 5- $\mu$ m sections using the RM2155 


\section{Cellular Physiology Cell Physiol Biochem 2018;46:1471-1482 \\ and Biochemistry Published online: April 24, $2018 \quad \begin{aligned} & \text { DOI 10159/2018 The Author(s). Published by S. Karger AG, Basel } \\ & \text { www.karger.com/cpb }\end{aligned}$}

Hu et al.: Bone Energy Metabolism and Histomorphometric Changes in Hyperthyroid

Rats

hard tissue microtome (Leica, Wetzlar, Germany). The unstained 8- $\mu \mathrm{m}$ sections were used for dynamic histomorphometric analysis. The 5- $\mu \mathrm{m}$ sections were stained with toluidine blue and Masson-Goldner trichome for static histomorphometric measurements. The TS was cut using the IsoMet low-speed saw, and sections were mounted on plastic slides, ground, and polished for histomorphometric analysis. A semiautomatic digitizing image analysis system (OsteoMetrics Inc., Decatur, GA) was used for quantitative bone histomorphometric measurements. The measured region of the PTM was the cancellous bone between 1 and $4 \mathrm{~mm}$ distal to the growth plate epiphyseal junction. Quantitative analysis was performed on one section of each sample. We used the abbreviations for bone histomorphometric parameters as recommended by the Histomorphometric Nomenclature Committee of the American Society for Bone and Mineral Research [8]. The following structural parameters were evaluated: total tissue volume, trabecular bone volume (BV), marrow volume, trabecular bone surface (BS), and osteoclast surface (OcS). Microarchitectural parameters (trabecular thickness, number [Tb.N], and separation [Tb.Sp]) were derived from the area and perimeter measurements. Measurements of dynamic parameters evaluated were single-labelled surface (sLS), doublelabelled surface, and inter-label width. Bone formation or resorption was assessed using the measurements of OcS per BS. Mineral apposition rate and ratio of the mineralizing surface to BS (calculated as 2.5 times the $\mathrm{sLS}$ ) bone formation rate per unit of BS (BFR/BS), and bone formation rate per unit of BV (BFR/BV) were analysed on unstained sections under ultraviolet light. The histomorphometric parameters measured in this study were consistent with those evaluated in previous studies [9-11].

\section{Protein preparation}

Three left femurs were selected from the two groups for iTRAQ investigation. Lysis buffer 3 (8 M urea, $40 \mathrm{mM}$ Tris-HCl or triethylammonium bicarbonate (TEAB) with $1 \mathrm{mM}$ phenylmethylsulfonyl fluoride (PMSF), $2 \mathrm{mM}$ ethylenediaminetetraacetic acid, and $10 \mathrm{mM}$ dithiothreitol [DTT], pH 8.5) with two magnetic beads (diameter $5 \mathrm{~mm}$ ) was used to extract the proteins. The mixtures were placed in a TissueLyser for 2 $\mathrm{min}$ at $50 \mathrm{~Hz}$ to release the proteins. After centrifugation at $25,000 \mathrm{~g}$ at $4^{\circ} \mathrm{C}$ for $20 \mathrm{~min}$, the supernatant was transferred to a new tube, reduced with $10 \mathrm{mM} \mathrm{DTT} \mathrm{at} 56^{\circ} \mathrm{C}$ for $1 \mathrm{~h}$, and alkylated with $55 \mathrm{mM}$ iodoacetamide in the dark at $25^{\circ} \mathrm{C}$ for $45 \mathrm{~min}$. Following centrifugation $\left(25,000 \mathrm{~g}, 4^{\circ} \mathrm{C}, 20 \mathrm{~min}\right)$, the supernatant containing the proteins was quantified using the Bradford assay. Protein quality and concentration were measured using SDS-PAGE and the Bradford assay.

\section{Protein digestion}

The protein solution $(100 \mu \mathrm{g})$ combined with $8 \mathrm{M}$ urea was diluted four times by adding $100 \mathrm{mM}$ TEAB. Trypsin Gold (Promega Corp., Madison, WI) was used for protein digestion at a protein to trypsin ratio of 40:1 at $37^{\circ} \mathrm{C}$ overnight. Next, the peptides were desalted using a Strata X C18 column (Phenomenex Inc., Torrance, CA) and vacuum dried according to the manufacturer's protocol as previously described [12].

The peptides were dissolved in $30 \mu \mathrm{L} 0.5 \mathrm{M}$ TEAB by vortexing. After the iTRAQ labelling reagents were restored to ambient temperature, they were combined with samples. Peptide labelling was performed using iTRAQ Reagent 8-plex kit according to the manufacturer's protocol as previously described [12]. Peptides labelled using different reagents were combined and desalted using the Strata X C18 column and vacuum dried [12].

Subsequently, peptides separation was performed by using a Shimadzu LC-20AB (Shimadzu Corp., Kyoto, Japan) high-performance liquid chromatography (HPLC) pump system coupled to a high-pH reversephase column, reconstituted to $2 \mathrm{~mL}$ with buffer A ( $5 \%$ acetonitrile $[\mathrm{ACN}]$ and $95 \% \mathrm{H}_{2} \mathrm{O}$; pH adjusted to 9.8 with ammonia), and loaded onto a column containing $5-\mu \mathrm{m}$ particles (Phenomenex). The peptides were then separated at a flow rate of $1 \mathrm{~mL} / \mathrm{min}$ with a gradient of $5 \%$ buffer $\mathrm{B}\left(5 \% \mathrm{H}_{2} \mathrm{O}\right.$ and $95 \% \mathrm{ACN}$; $\mathrm{pH}$ adjusted to 9.8 with ammonia) for $10 \mathrm{~min}, 5-35 \%$ buffer B for $40 \mathrm{~min}$, and 35-95\% buffer B for $1 \mathrm{~min}$. The system was then maintained in $95 \%$ buffer B for $3 \mathrm{~min}$ and decreased to $5 \%$ within 1 min before equilibrating with $5 \%$ buffer B for $10 \mathrm{~min}$. The elution was monitored by measuring the absorbance at $214 \mathrm{~nm}$, and fractions were collected every $1 \mathrm{~min}$. Eluted peptides were pooled into 20 fractions and then dried in a vacuum chamber.

Liquid Chromatography Electrospray Ionization Tandem Mass Spectrometric analysis based on a Triple TOF 5600 System

Individual fractions were resuspended in buffer $\mathrm{A}$ and centrifuged at 20, $000 \mathrm{~g}$ for $10 \mathrm{~min}$. The supernatant was collected and loaded onto a C18 trap column at $5 \mu \mathrm{L} / \mathrm{min}$ for $8 \mathrm{~min}$ using an LC-20AD nanoHPLC system (Shimadzu) via the autosampler. Thereafter, the peptides were eluted from the trap column 


\section{Cellular Physiology Cell Physiol Biochem 2018;46:1471-1482 \\ \begin{tabular}{l|l} 
and Biochemistry Published online: April 24, 2018 & $\begin{array}{l}\text { C } 2018 \text { The Author(s). Published by S. Karger AG, Basel } \\
\text { www.karger.com/cpb }\end{array}$
\end{tabular}}

Hu et al.: Bone Energy Metabolism and Histomorphometric Changes in Hyperthyroid

Rats

and separated using an analytical C18 column (inner diameter, $75 \mu \mathrm{m}$ ) packed in-house. The gradient was run at $300 \mathrm{~nL} / \mathrm{min}$ from $8 \%$ to $35 \%$ of buffer B in $35 \mathrm{~min}$, increasing to $60 \%$ in $5 \mathrm{~min}$, with maintenance at $80 \%$ buffer B for $5 \mathrm{~min}$, and finally returning to $5 \%$ in $0.1 \mathrm{~min}$ with equilibration for $10 \mathrm{~min}$.

Data acquisition was performed using a Triple TOF 5600 System (SCIEX, Framingham, MA) equipped with a Nanospray III source (SCIEX) and a pulled quartz tip as the emitter (New Objective Inc., Woburn, MA) and controlled using Analyst 1.6 software (AB SCIEX, Concord, ON, Canada). Data were acquired using the following MS conditions: ion spray voltage of 2, $300 \mathrm{~V}$, curtain gas of 30 psi, nebulizer gas of 15 psi, and temperature of the interface heater of $150^{\circ} \mathrm{C}$. High-sensitivity mode was used throughout for data acquisition. The accumulation time for first mass spectrometry survey (MS1) was $250 \mathrm{~ms}$, and the mass range was 350-1500 Da. Based on the intensity in the MS1 survey, as many as 30 product ion scans were obtained when a threshold of 120 counts per second was exceeded with a charge state of $2+$ to $5+$. The dynamic exclusion was set to half of the peak width (12 s). For iTRAQ data acquisition, the collision energy was adjusted for collision-induced dissociation of all precursor ions, and the Q2 transmission window for 100 Da was $100 \%$.

\section{iTRAQ data analysis}

After obtaining raw data, we performed a bioinformatics analysis. Identification of proteins from the tandem mass spectra by searching of the database has been widely adopted. General guidelines for database selection were applied. Single-species protein databases were considered suitable for protein identification. If there was no species-specific protein database, we selected a larger database. In addition, genome and transcriptome databases were considered suitable for protein identification. Raw MS/MS spectra data were converted into Mascot generic format (MGF) using ProteoWizard tool msConvert, and the exported MGF files were searched using Mascot version 2.3.02 in this project against the selected database. At least one unique peptide was necessary for identification of a protein. The automated IQuant software was used for quantitative analysing analysis of the labelled peptides with isobaric tags. IQuant integrates Mascot Percolator, a high-performance machine learning method for rescoring database search results, to provide reliable significance measures. To assess the confidence of the peptides, the peptide-spectrum matches (PSMs) were pre-filtered at a PSM-level false discovery rate (FDR) of 1\%. Thereafter, based on the "simple principle" (parsimony principle), the identified peptide sequences were assembled into a set of confident proteins. To control the rate of false-positive results at the protein level, a protein FDR at 1\%, which was based on the selected protein FDR strategy, was estimated after protein inference (protein-level FDR $\leq$ 0.01). The protein quantification process included the following steps: identification of proteins, correction of tag impurity, normalization of data, imputation of missing values, calculation of protein ratio, statistical analysis, and presentation of data.

\section{Bioinformatic analyses}

All proteins with an FDR less than 1\% were selected for downstream analysis. We performed deep analysis based on the differentially expressed proteins (DEPs), including the Gene Ontology (GO) and Kyoto Encyclopedia of Genes and Genomes (KEGG) pathway enrichment analyses.

\section{Western blotting}

Simple western blotting was used to complete most of the procedures in the same sample tube automatically, including loading the sample and separating proteins in the sample, immobilizing the separated proteins to the capillary wall, using an immunoprobe for the specific protein, and performing an automatic data analysis. Total protein extraction and concentration measurement was conducted prior to this analysis. After diluting the sample and antibody to an appropriate concentration and loading the sample according to the Wes Mouse (12-230 kDa) Master Kit 200 data points: PS - MK04 Protein Simple Kit instruction, the experimental results were obtained after an approximately $3 \mathrm{~h}$ run in the instrument. The primary antibodies (Cs and Cox5a, Abcam Inc., Cambridge, MA; Ogdh, Idh3a, ATP5a1, LDHa, and PFKM, Proteintech Group Inc., Rosemont, IL) and $\beta$-actin (Sangon Biotech Co. Ltd., Shanghai, China) were diluted 1:50. Parameter settings of the instrument for each process were: separation of the proteins (375 V, $25 \mathrm{~min})$, incubation with primary antibody (30 min), incubation with secondary antibody (30 min), and blocking (15 $\min )$. 


\section{Cellular Physiology Cell Physiol Biochem 2018:46:1471-1482 \\ and Biochemistry Published online: April 24, $2018 \quad \begin{aligned} & \text { DOI 1015918 The Author(s). Published by S. Karger AG, Basel } \\ & \text { www.karger.com/cpb }\end{aligned}$}

Hu et al.: Bone Energy Metabolism and Histomorphometric Changes in Hyperthyroid

Rats

All the analyses were performed by technicians in a blinded manner. Continuous variables were shown as means \pm standard errors; statistical evaluations were performed using EmpowerStats software, and all $p$-values $<0.05$ were defined as statistically significant.

\section{Results}

\section{Levels of serum indicators and weight}

After treatment, the levels of total T4, total T3, and markers of bone turnover were higher in the hyperthyroid rats than in the control animals. $\mathrm{Ca}^{2+}$ levels and weight were significantly lower in hyperthyroid rats compared to controls (all $p<0.05$ ). There were no statistically significant differences in any other indicators between these two groups. Details are presented in Table 1.

\section{Bone changes in hyperthyroid rats}

Compared with euthyroid rats, hyperthyroid animals showed reduced fifth lumbar vertebral and whole femur BMD ( $p=0.033$ and 0.027, respectively). Histomorphometry of the PTM revealed that the percentage trabecular area and Tb.N in hyperthyroid rats were significantly decreased, whereas bone formation rates (BFR/BV and BFR/BS), the percentage of osteoclast perimeter, and Tb.SP in hyperthyroid rats were significantly increased (all $p<0.05$ ) compared with control rats. The biomechanical parameters of the femur in the hyperthyroid rats showed a trend toward a decrease, and the parameters of maximum, fracture, and elastic loads were all significantly different between the case and control groups. Details are presented in Table 2, and representative bone changes in the hyperthyroid and control rats are shown in Fig. 1-3.

\section{Proteins identified in femoral tissue}

A total of 413, 675 spectra were generated in the ITRAQ quantification, and 24, 582 peptides and 5, 227 proteins were identified with 1\% FDR. Most peptides ranged in length from 5 to 45 residues, with the maximum number of proteins being 9 residues (Fig. 4). More than $65.03 \%$ of the proteins contained at least two unique peptides among the identified proteins (Fig. 5).

\section{KARGER}

Table 1. Levels of serum indicators and body weight. Data are presented as means \pm standard errors. TT4, total T4; TT3, total T3; OC, osteocalcin; ALP, alkaline phosphatase; $\beta$-CTX, beta-crosslaps; TRACP, tartrate-resistant acid phosphatase

\begin{tabular}{llll}
\hline & Hyperthyroid rats & Control rats & $p$-value \\
\hline TT4 $(\mathrm{nmol} / \mathrm{L})$ & $135.83 \pm 19.76$ & $43.54 \pm 4.76$ & $<0.001$ \\
TT3 $(\mathrm{nmol} / \mathrm{L})$ & $3.81 \pm 0.36$ & $1.48 \pm 0.11$ & $\ll 0.001$ \\
OC $(\mathrm{ng} / \mathrm{mL})$ & $44.65 \pm 3.15$ & $28.88 \pm 0.97$ & $\ll 0.001$ \\
ALP $(\mathrm{U} / \mathrm{L})$ & $119.22 \pm 8.07$ & $78.91 \pm 9.39$ & 0.0058 \\
$\beta$-CTX $(\mathrm{ng} / \mathrm{mL})$ & $1.37 \pm 0.07$ & $0.84 \pm 0.06$ & 0.0001 \\
TRACP $(\mathrm{U} / \mathrm{L})$ & $114.24 \pm 8.26$ & $75.99 \pm 8.41$ & 0.006 \\
Ca ${ }^{2+}(\mathrm{mmol} / \mathrm{L})$ & $2.49 \pm 0.01$ & $2.59 \pm 0.03$ & 0.035 \\
P (mmol/L) & $2.19 \pm 0.05$ & $2.05 \pm 0.13$ & 0.358 \\
Initial weight (g) & $389.13 \pm 10.25$ & $383.75 \pm 10.29$ & 0.717 \\
Final weight $(\mathrm{g})$ & $479.75 \pm 12.82$ & $528.54 \pm 15.86$ & 0.031 \\
\hline
\end{tabular}

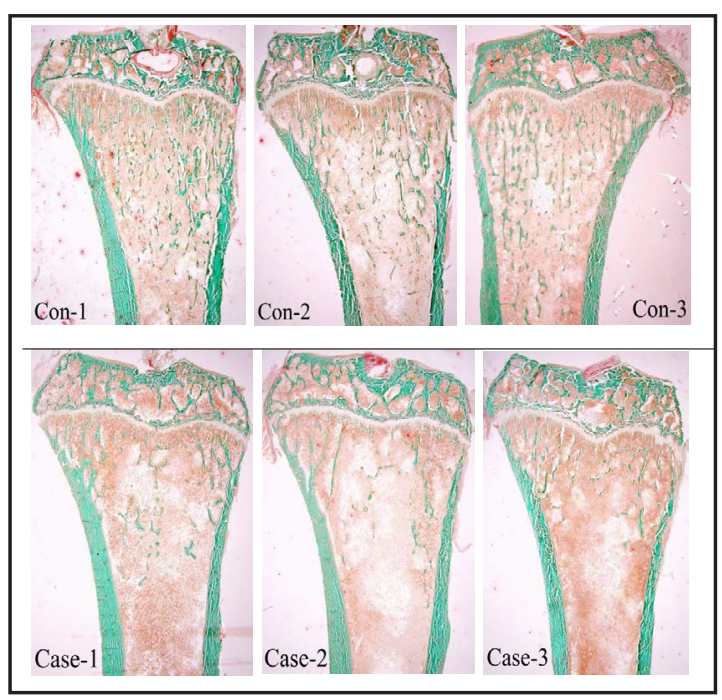

Fig. 1. Representative Masson-Goldner trichrome staining of the proximal tibial metaphysis from the hyperthyroid and control rats. Scale bar, $5 \mu \mathrm{m}$. 


\section{Cellular Physiology Cell Physiol Biochem 2018;46:1471-1482

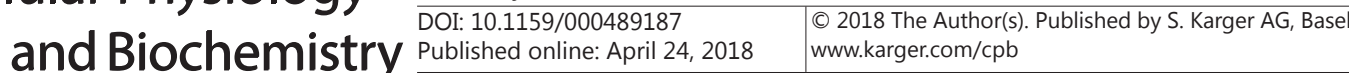

Hu et al.: Bone Energy Metabolism and Histomorphometric Changes in Hyperthyroid Rats

Fig. 2. Representative calcein double labelling of the proximal tibial metaphysis from the hyperthyroid and control rats; the arrows indicate single fluorescence in the control rats and double fluorescence in the hyperthyroid rats. Scale bar, $8 \mu \mathrm{m}$.
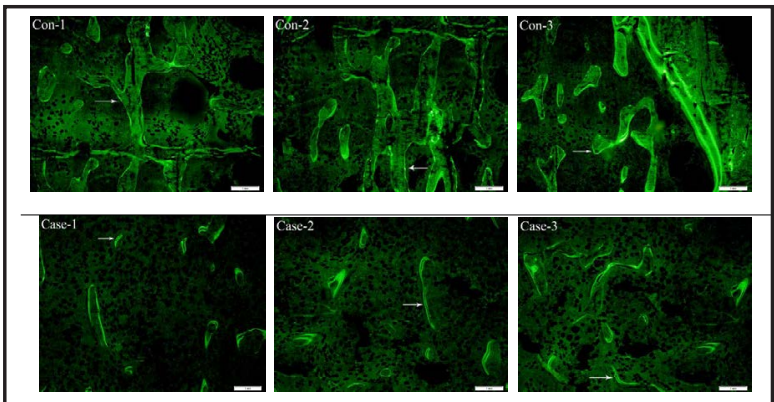

Table 2. Parameters of bone change in rats. Data are presented as means \pm standard errors. BMD, bone mineral density; \%Tb.Ar, percentage of the trabecular area; Tb.N, trabecular number; Tb.Sp, trabecular separation; MAR, mineral apposition rate; $\mathrm{BFR} / \mathrm{BV}$, bone formation rate per unit of bone volume; $\mathrm{BFR} / \mathrm{TV}$, bone formation rate per unit of total tissue area; BFR/BS, bone formation rate per unit of bone surface; Oc.Pm, percentage of the osteoclast perimeter; Ct.Ar, percentage of the cortical bone area; E-MAR, endosteal mineral apposition rate; \%L.Pm, Percentage of the labelled perimeter; OC.N, osteoclast number; \%Ob.Pm, percentage of the osteoclast perimeter; \%Ma.AR, marrow area/ total tissue area×100; \%P-L.Pm, (double-labelled perimeter+single-labelled perimeter/2)/periosteal perimeter $\times$ 100; P-MAR, inter-labelled width/interval; P-BFR/BS, periosteal bone formation rate per unit of bone surface; \% E-L. Pm, (double-labelled perimeter+singlelabelled perimeter/2)/endocortical perimeter $\times 100$; E-BFR/BS, endocortical bone formation rate per unit of bone surface; Tb.Wi, trabecula bone width; $d$, day; a, year

\begin{tabular}{|c|c|c|c|}
\hline & Hyperthyroid rats & Control rats & $p$-value \\
\hline \multicolumn{4}{|l|}{$\operatorname{BMD}\left(\mathrm{g} / \mathrm{cm}^{2}\right)$} \\
\hline Lumbar vertebral & $0.263 \pm 0.004$ & $0.280 \pm 0.006$ & 0.031 \\
\hline Entire femur & $0.2712 \pm 0.006$ & $0.293 \pm 0.007$ & 0.026 \\
\hline \multicolumn{4}{|l|}{ Bone biochemistry } \\
\hline Stiffness (N) & $413.95 \pm 16.89$ & $450.06 \pm 24.06$ & 0.24 \\
\hline Maximum load (N) & $157.30 \pm 5.84$ & $182.89 \pm 9.12$ & 0.033 \\
\hline Fracture load $(\mathrm{N})$ & $150.82 \pm 6.16$ & $177.96 \pm 9.41$ & 0.030 \\
\hline Elastic load (N) & $114.84 \pm 5.49$ & $131.06 \pm 4.67$ & 0.022 \\
\hline \multicolumn{4}{|l|}{ Histomorphometry } \\
\hline$\% \mathrm{~Tb} . \mathrm{Ar}$ & $8.19 \pm 0.73$ & $15.96 \pm 1.45$ & 0.004 \\
\hline Tb.N (/mm) & $1.35 \pm 0.12$ & $2.63 \pm 0.20$ & 0.002 \\
\hline Tb.Wi $(\mu \mathrm{m})$ & $61.00 \pm 2.67$ & $60.55 \pm 1.32$ & 0.91 \\
\hline Tb.Sp $(\mu \mathrm{m})$ & $716.35 \pm 74.04$ & $332.81 \pm 36.73$ & 0.009 \\
\hline \%L.Pm & $26.27 \pm 2.29$ & $17.04 \pm 3.71$ & 0.11 \\
\hline $\operatorname{MAR}(\mu \mathrm{m} / \mathrm{d})$ & $1.99 \pm 0.13$ & $1.73 \pm 0.18$ & 0.366 \\
\hline BFR/BV (\%/a) & $513.19 \pm 35.24$ & $294.28 \pm 74.21$ & 0.050 \\
\hline BFR/TV (\%/a) & $42.45 \pm 5.43$ & $46.53 \pm 11.90$ & 0.79 \\
\hline $\mathrm{BFR} / \mathrm{BS}(\% / \mathrm{a})$ & $50.78 \pm 2.58$ & $28.85 \pm 6.94$ & 0.032 \\
\hline OC.N $(/ \mathrm{mm})$ & $0.84 \pm 0.18$ & $0.47 \pm 0.06$ & 0.105 \\
\hline$\%$ Oc.Pm & $3.00 \pm 1.03$ & $1.26 \pm 0.17$ & 0.018 \\
\hline$\%$ Ob.Pm & $4.45 \pm 2.13$ & $0.36 \pm 0.08$ & 0.103 \\
\hline$\% \mathrm{Ct} . \mathrm{Ar}$ & $79.18 \pm 1.17$ & $82.78 \pm 1.11$ & 0.050 \\
\hline \%Ma.Ar & $19.16 \pm 6.28$ & $18.409 \pm 1.34$ & 0.670 \\
\hline \%P-L.Pm & $61.00 \pm 6.37$ & $45.81 \pm 0.95$ & 0.105 \\
\hline P-MAR $(\mu \mathrm{m} / \mathrm{d})$ & $5.49 \pm 0.58$ & $4.77 \pm 2.33$ & 0.532 \\
\hline P-BFR/BS $\left(\mu \mathrm{m} / \mathrm{d}^{*} 100\right)$ & $334.65 \pm 42.26$ & $235.97 \pm 64.60$ & 0.230 \\
\hline \%E-L.Pm & $20.29 \pm 1.86$ & $14.22 \pm 3.09$ & 0.123 \\
\hline E-MAR $(\mu \mathrm{m} / \mathrm{d})$ & $2.029 \pm 0.18$ & $0.102 \pm 0.06$ & $<0.01$ \\
\hline E-BFR/BS $(\mu \mathrm{m} / \mathrm{d} \times 100)$ & $4.95 \pm 2.48$ & $2.03 \pm 1.49$ & 0.337 \\
\hline
\end{tabular}

Fig. 3. Representative calcein double labelling of the tibial cross-section from the hyperthyroid and control rats. Scale bar, $8 \mu \mathrm{m}$.
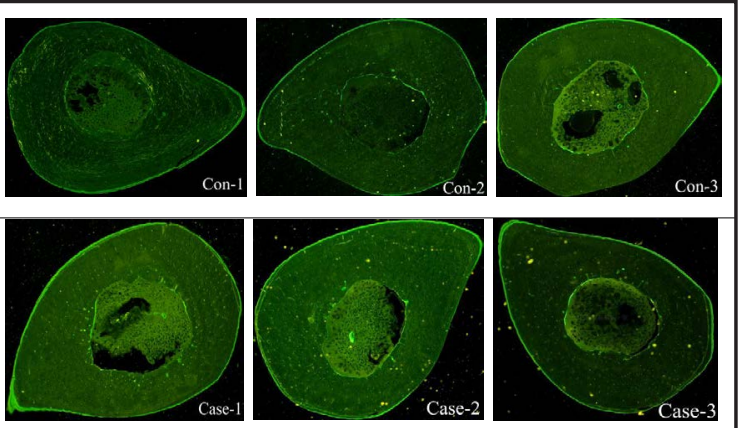
Hu et al.: Bone Energy Metabolism and Histomorphometric Changes in Hyperthyroid Rats

DEPs identified using ITRAQ quantification

In this study DEPs were defined as proteins with a 1.2-fold change and a Q-value of less than 0.05. The final DEPs were defined in at least one experiment. Overall, the expression levels of the 1,310 proteins were significantly different between the hyperthyroid and euthyroid rats (711 proteins were upregulated and 599 were downregulated in the hyperthyroid rats; Fig. 6).

\section{Quantification repeat analysis}

We used the coefficient of variation (CV = standard deviation / mean) to evaluate reproducibility; lower CVs indicate better reproducibility. Here, the mean $\mathrm{CV}$ was $17 \%$, which indicates a high reproducibility (Fig. 7).

\section{GO and KEGG enrichment analyses of DEPS}

The results of the cellular component analysis showed that $16.4 \%$ of the proteins were located in the extracellular region, $11.6 \%$ in the mitochondrial region, and $2.7 \%$ in the mitochondrial respiratory chain. Meanwhile, the results of the molecular function analysis indicated that $11.4 \%$ of the proteins were associated with the structural molecular activity, 9.0\% with $\mathrm{Ca}^{2+}$ binding, $4.3 \%$ with endopeptidase regulator activity, and $4.7 \%$ with peptidase regulator activity. For biological process, DEPs were mainly involved in the generation of precursor metabolites and energy

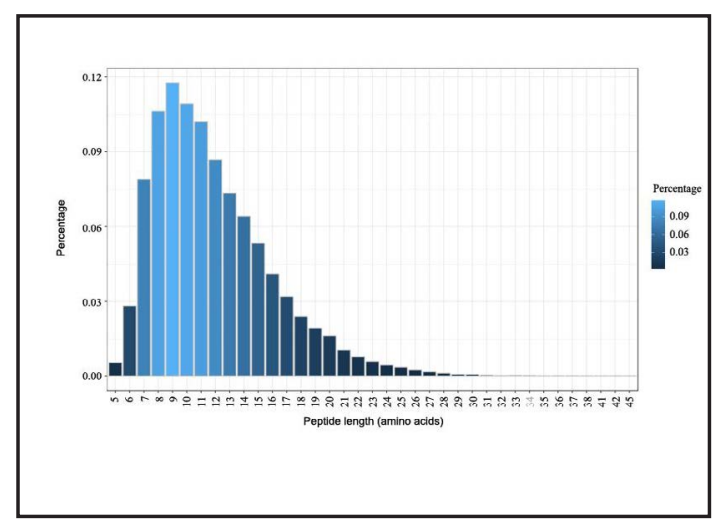

Fig. 4. Peptide length distribution. The percentage of different peptide lengths; $x$-axis: peptide length; $\mathrm{y}$-axis: corresponding peptide percentage.

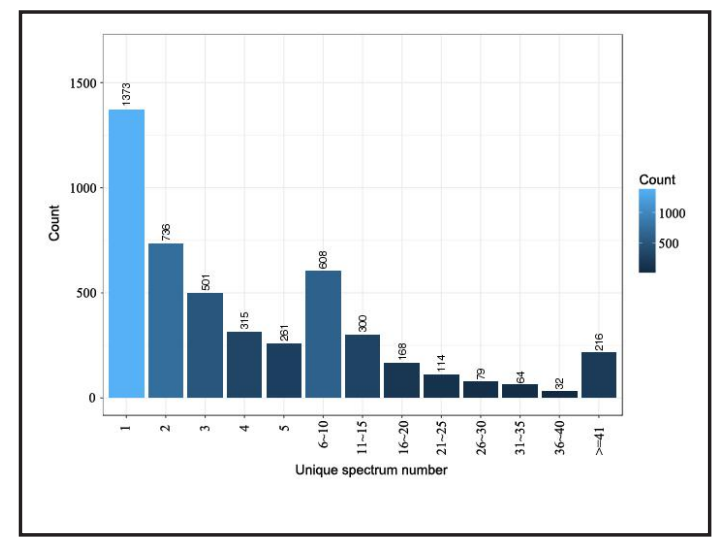

Fig. 5. Unique peptide number distribution. The $\mathrm{x}$-axis shows the unique peptide number of each protein, and the y-axis shows the corresponding protein number. Most of the identified proteins contained less than 10 peptides and the protein quantity decreased with the increase in number of peptides.

Fig. 6. Differentially expressed proteins. The x-axis shows the comparison group; the $y$-axis indicates the number of differentially expressed proteins. The red column indicates the upregulated proteins; the green column indicates the downregulated proteins.

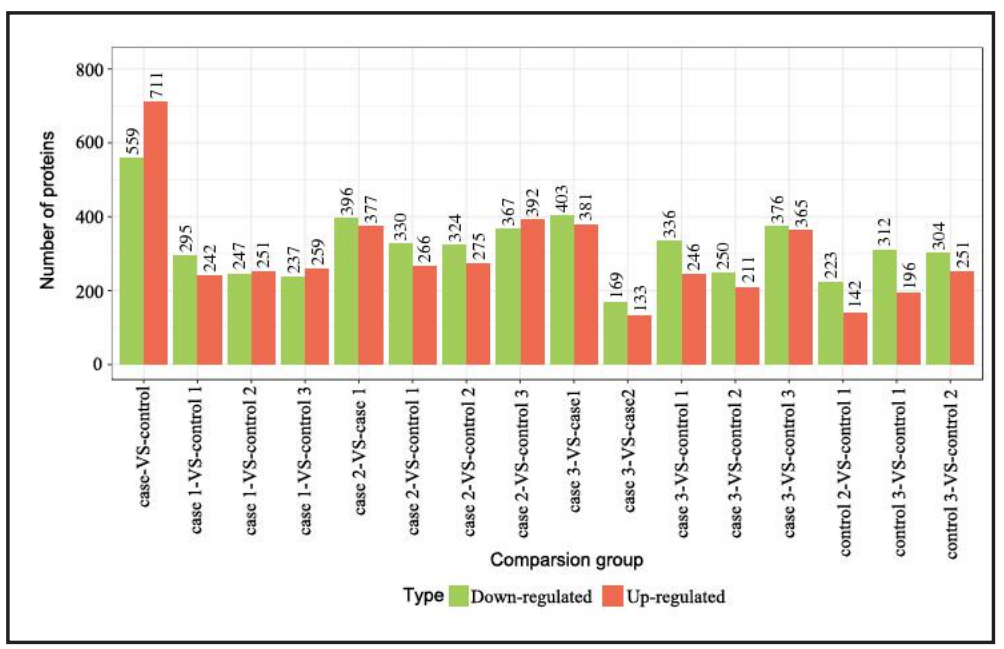


Fig. 7. Coefficient of variation (CV) distribution. The $\mathrm{x}$-axis indicates the deviation between the protein ratio of the repetitive samples. The $y$-axis indicates the percentage of the protein with a quantified amount at a certain angle.

u et al.: Bone Energy Metabolism and Histomorphometric Changes in Hyperthyroid C 2018 The Author(s). Published by S. Karger AG, Basel ats
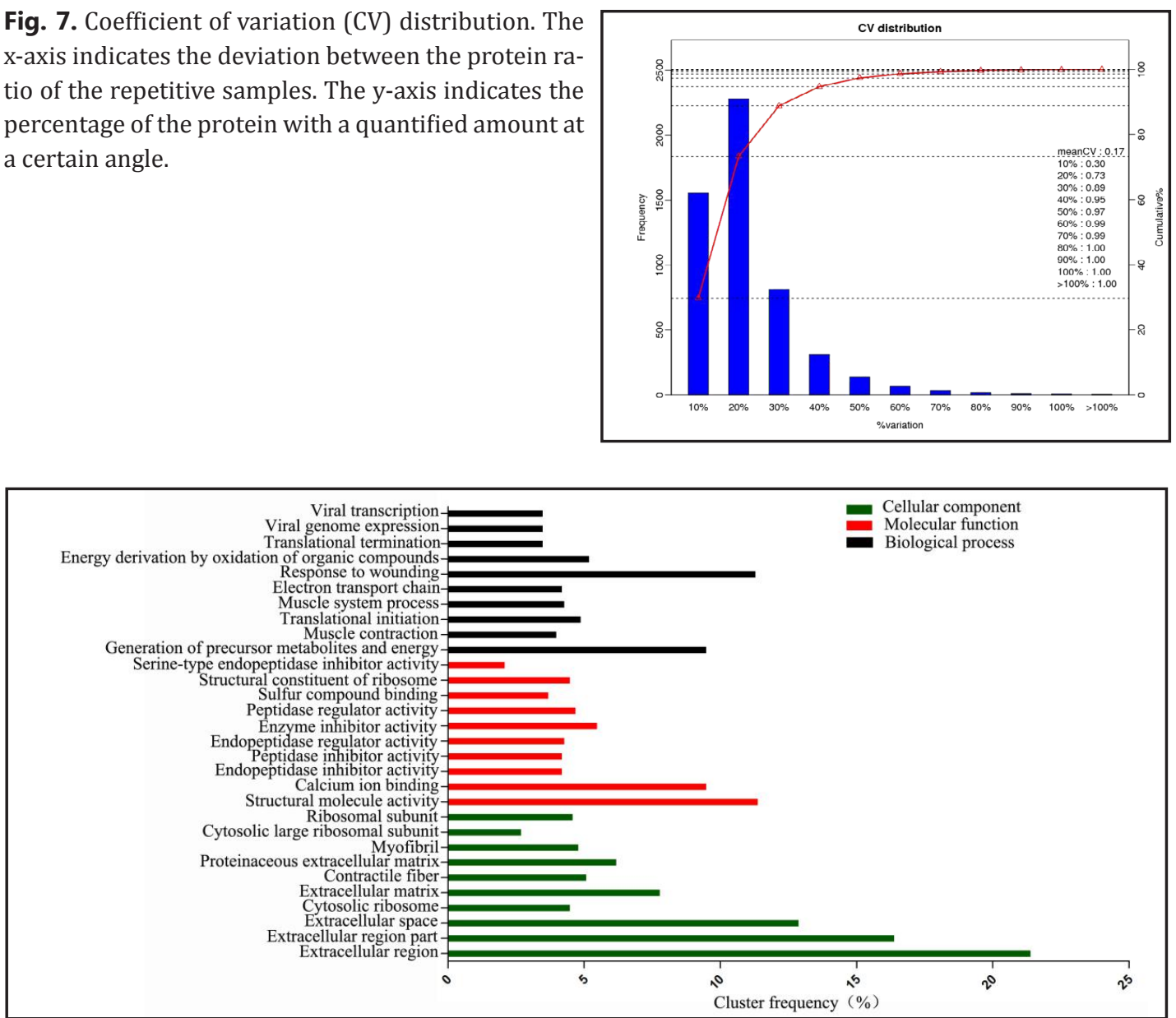

Fig. 8. Gene Ontology enrichment of the differentially expressed proteins.

Fig. 9. Pathway enrichment of the differentially expressed proteins in each pairwise group comparison. The enrichment factor is the ratio of the differentially expressed protein number annotated in this pathway term to all protein number annotated in this pathway term. A higher rich factor indicates greater intensiveness. The $\mathrm{p}$-value ranges from 0 to 1 , and lower $\mathrm{p}$-values indicate greater intensiveness. The top 20 enriched pathway terms are shown.

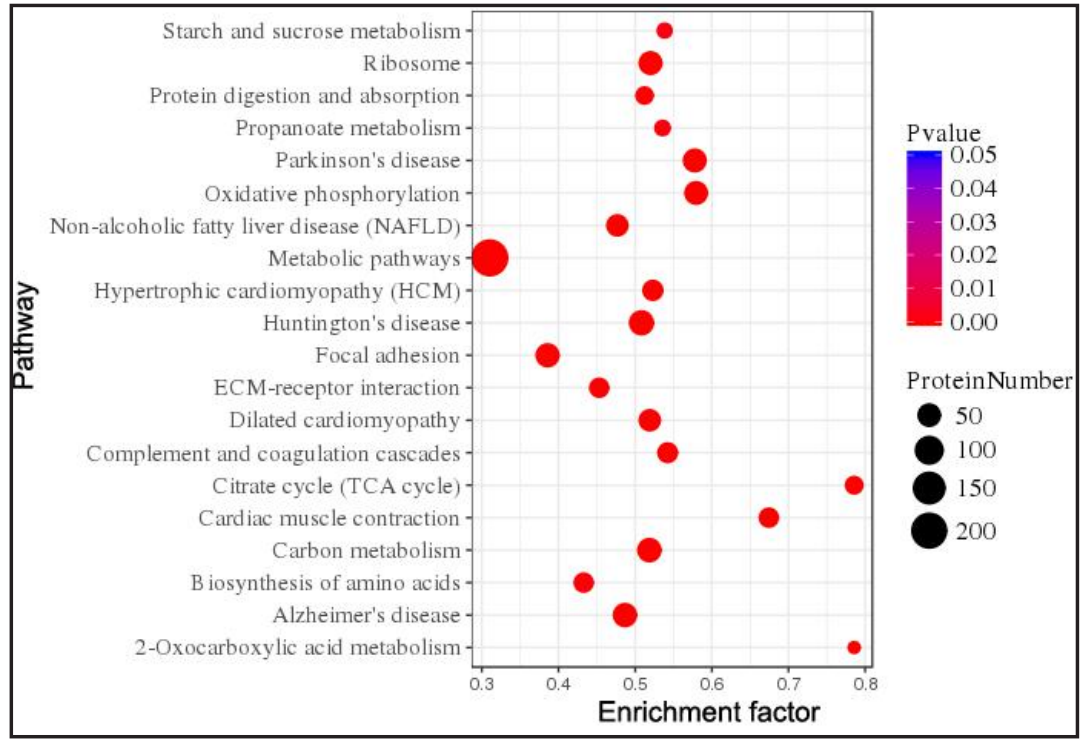


Hu et al.: Bone Energy Metabolism and Histomorphometric Changes in Hyperthyroid Rats

(9.5\% of DEPs), muscle contraction $(4.0 \%)$, the electron transport chain (4.2\%), the tricarboxylic acid (TCA) cycle $(1.4 \%)$, and oxidative phosphorylation (1.5\%). Fig. 8 shows the top 10 terms for cellular component, molecular function, and biological process.

Fig. 9 shows the top 20 items of the KEGG enrichment results, demonstrating that eight terms among the top 20 significant pathways were related to metabolism, and those related to oxidative phosphorylation and the TCA cycle were mainly involved in mitochondrial energy metabolism. Furthermore, the glycolysis pathway was the 21st significant pathway among all the KEGG pathways. In addition to one protein involved in the TCA cycle, seven proteins were involved in oxidative phosphorylation and two in glycolysis were downregulated in the hyperthyroid rats; the other proteins were upregulated (Fig. 10). Moreover, all the key proteins involved in the TCA cycle-oxidative phosphorylation and glycolysis were significantly upregulated in the hyperthyroid rats. In general, the quantitative proteomic results demonstrated that mitochondrial energy metabolism and anaerobic glycolysis were associated with bone changes induced by T4 (Fig. 11).
Fig. 10. Overview of the glycolysistricarboxylic acid (TCA) cycle-Oxidative phosphorylation pathway proteins.
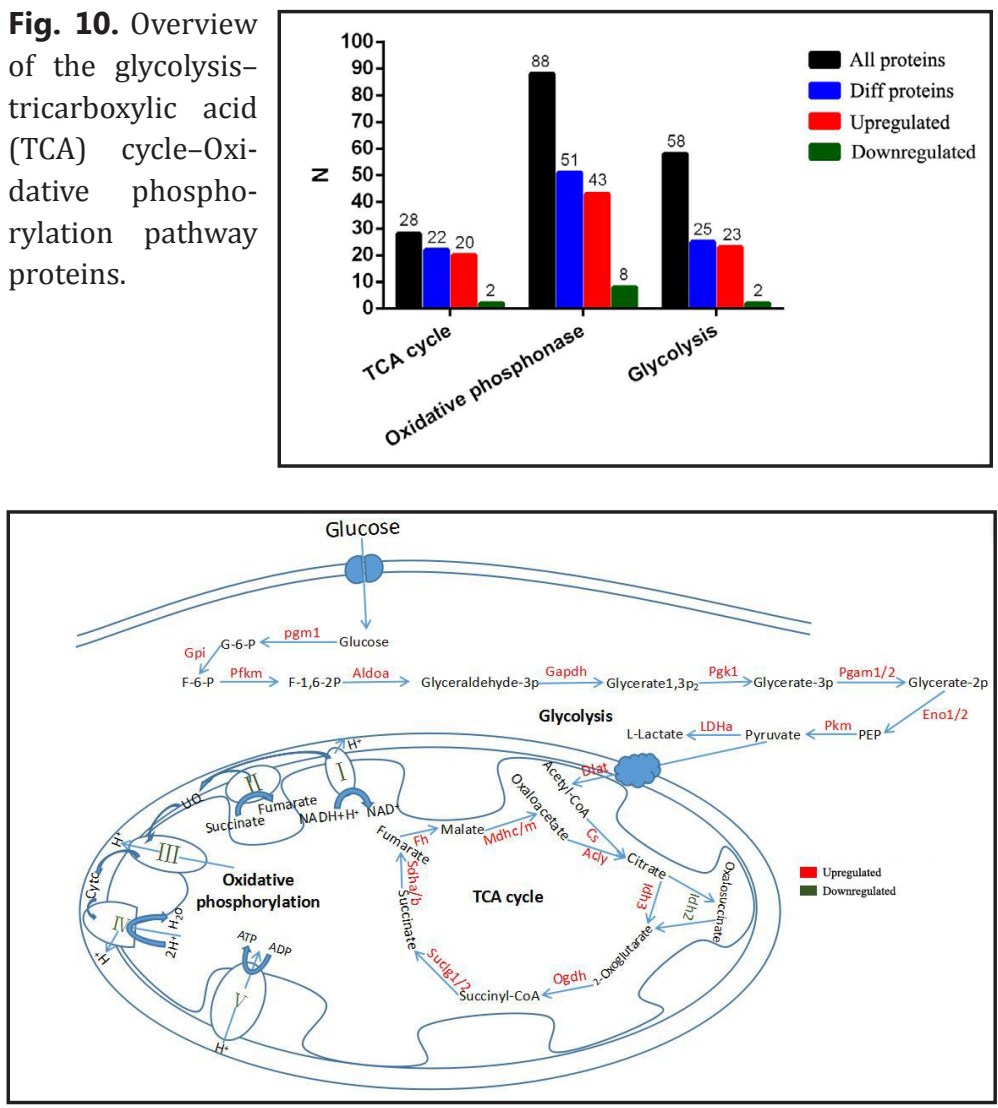

Fig. 11. Glycolysis-tricarboxylic acid (TCA) cycle-oxidative phosphorylation pathway in the bone of hyperthyroid rats (differentially expressed proteins are partly annotated).

Fig. 12. Seven differentially expressed proteins confirmed to contribute in the glycolysis-tricarboxylic acid cycle-oxidative phosphorylation pathway using simple western blotting. (a) Simple western blotting results of $\mathrm{CS}$, Ogdh, Idh3a, Atp5a1, Cox5a, PFKM, and LDHa proteins. $\beta$-actin was used as the internal control. (b) Statistical analysis of the simple western blotting results. Data are presented as means \pm standard errors ( $\mathrm{n}=4$ vs. 4 ). The mean value of the control

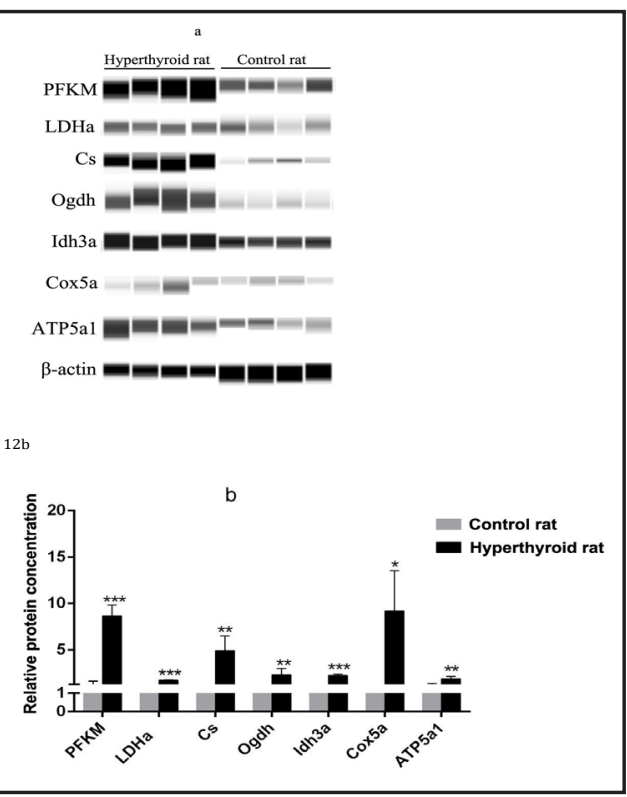
rats was set as $1 .{ }^{*} \mathrm{p}>0.05 ;{ }^{* *} \mathrm{p}<0.05,{ }^{* * *} \mathrm{p}<0.001$. 


\section{Cellular Physiology Cell Physiol Biochem 2018;46:1471-1482 \\ and Biochemistry Published online: April 24, $2018 \quad$\begin{tabular}{l|l} 
DOI: 10.1159/000489187 & $\begin{array}{l}\text { C) } 2018 \text { The Author(s). Published by S. Karger AG, Basel } \\
\text { www.karger.com/cpb }\end{array}$
\end{tabular} \\ Hu et al.: Bone Energy Metabolism and Histomorphometric Changes in Hyperthyroid \\ Rats}

Selected DEPs in the energy metabolic pathway confirmed by simple western blotting

Seven proteins involved in the glycolysis-TCA cycle-oxidative phosphorylation pathway were selected to verify the iTRAQ data (Fig. 12). Except for Cox5a $(p=0.054)$, the results of the simple western blotting analysis showed that the expression of the selected DEPs was significantly greater in the hyperthyroid rats than in the control rats, which is consistent with the iTRAQ results. Among these seven proteins, three were key enzymes of the TCA cycle (CS, Ogdh, and Idh3a), two were oxidative phosphorylation-related proteins (Atp5a1 and Cox5a), and the other two were glycolysis-related proteins (PFKM and LDHa).

\section{Discussion}

We have confirmed previous findings of bone change in hyperthyroidism and verified the characteristics of osteoporosis in subjects with hyperthyroidism in a male rat model. Excessive levels of thyroid hormones could cause net bone loss by decreasing BV and BMD, leading to the development of osteoporosis. Moreover, excessive thyroid hormone levels could further increase the high bone turnover rate by increasing the BFR and resorption rate simultaneously according to the static and dynamic histomorphometric parameters, confirmed by the higher serum levels of bone turnover markers. However, the activity of osteoclasts might be higher than the activity of osteoblasts, and adult skeletal mass might not be maintained with the uncoupling of bone formation and resorption. Clinical studies have shown that bone is sensitive to thyroid function, and even mild thyroid dysfunction might have serious adverse effects on skeletal health [13-15]. Coincidentally, some retrospective and prospective cohort studies have also shown that a history of hyperthyroidism can increase the risk of fractures [16-19]. Accordingly, in the present study, the bones of hyperthyroid rats became weaker than those of control rats based on the change in bone biomechanical properties.

In our proteomic study we found that 23 enzymes involved in glycolysis, 20 in the TCA cycle, and 43 in oxidative phosphorylation were upregulated in the bones of hyperthyroid rats compared with controls. Due to excessive levels of T4 in the bones, all the key enzymes in the glycolysis-TCA cycle-oxidative phosphorylation pathway were upregulated. Further, all the enzymes that contributed to the process of ATP production were also upregulated. These results indicate that ATP synthesis and glucose catabolism were considerably increased in the femoral tissues of the hyperthyroid rats. It has previously been found that bones play an essential role in whole-body glucose homeostasis, and bone remodelling is a dynamic ATP-consuming process that occurs via glucose catabolism [20-23]. T4 has been shown to accelerate the rates of oxygen consumption and heat production in various body tissues [7]. Multiple metabolizing enzymes involved in glucose, fat, and protein metabolism were also found to be stimulated by the thyroid hormones. Only a few studies have demonstrated that the thyroid hormones are involved in energy metabolism of bone tissue; however, based on our results, we speculate that $\mathrm{T} 4$ also stimulates the metabolizing enzymes involved in glucose anaerobic degradation and aerobic oxidation in bone tissues. More importantly, excessive T4 treatment seems to induce more active glucose catabolism and dynamic ATP consumption to increase the rate of bone turnover and allow more active bone remodelling. Therefore, inhibiting hyperactivation of the glycolysis-TCA cycle-oxidative phosphorylation pathway and normalizing energy metabolism might provide a therapeutic target in hyperthyroidrelated osteoporosis.

It has been reported that aerobic glycolysis primarily provided ATP rapidly to support mature osteoblast active biosynthesis in several extracellular matrix proteins, and oxidative phosphorylation increased when mature osteoblasts were involved in the process of mineralization [24]. Conversely, the proteins involved in the metabolic pathways of glycolysis, the TCA cycle, and oxidative phosphorylation were all upregulated during RANKL-stimulated osteoclastogenesis; the ATP consumption in bone resorption associated with bone matrix degradation was mainly derived from glycolysis [22]. In vitro quantitative proteomics results also indicated that DEPs involved in energy metabolism 


\section{Cellular Physiology Cell Physiol Biochem 2018;46:1471-1482 and Biochemistry Published online:April 24, $2018 \quad \begin{aligned} & \text { DOI 1018 } 2018 \text { The Author(s). Published by S. Karger AG, Basel } \\ & \text { www.karger.com/cpb }\end{aligned}$ \\ Hu et al.: Bone Energy Metabolism and Histomorphometric Changes in Hyperthyroid}

play an important role in osteoclastogenesis and bone resorption $[25,26]$. Similarly, in an in vivo study, we found that not only were the enzymes that contributed to the oxidation of pyruvate through the TCA cycle coupled with oxidative phosphorylation under excessive T4 treatment but also the enzymes that catalysed the conversion of glucose to lactate were upregulated; this might induce rapid and increased osteoblast and osteoclast active biosynthesis with ATP. Excessive thyroid hormone levels might promote both osteoclast and osteoblast bioenergetics by stimulating the glycolysis-TCA cycle-oxidative phosphorylation pathway. Furthermore, we hypothesize that metabolic disease-related osteoporosis, such as thyrotoxicosis, is fundamentally a disease involving energy metabolism and associated with abnormal glucose metabolism in the bone. There are also data showing that in vitro thyroid hormones affect the energy metabolism in the bone remodelling process. T4 has been found to induce bone formation, differentiation, and mineralization in osteoblast- or osteoblast-like cells $[27,28]$; more importantly, Gouveia et al. revealed that T3 acted on the osteoblast-like cell mitochondrial gene ATPase 6 [29]. Although Kanatani et al. discovered that T3 directly stimulated osteoclast differentiation [6] and Ma and Dai suggested that T3 stimulated osteoclast differentiation indirectly [30], only a few studies have investigated the effect of T4 on osteoclasts. Further studies to examine the specialization of these cells induced by $\mathrm{T} 4$ are needed.

\section{Conclusion}

In summary, in the present study we characterized the histomorphometric changes due to high-dose T4 treatment for 2 months in male rats and found that the changes in bone remodelling were associated with glucose energy metabolism, especially via the glycolysisTCA cycle-oxidative phosphorylation pathway. This finding provides new insight into the mechanisms of bone loss in hyperthyroidism.

\section{Acknowledgements}

This research was supported by the National Science Foundation of China (No. 81273518 and 81673814).

\section{Disclosure statement}

All the authors declare no conflicts of interest.

\section{References}

1 Hu ZQ Du MQ, Cui L: Research progress of osteoporosis in patients with hyperthyroidism. Chinese General Practice 2017;20:3187-3190.

-2 Tsourdi E, Rijntjes E, Köhrle J, Hofbauer LC, Rauner M: Hyperthyroidism and hypothyroidism in male mice and their effects on bone mass, bone turnover, and the Wnt inhibitors sclerostin and Dickkopf-1. Endocrinology 2015;156:3517-3527.

- 3 Obermayer-Pietsch B, Dobnig H, Warnkross H, Dimai HP, Weber K, Berghold A, Leb G: Variable bone mass recovery in hyperthyroid bone disease after radioiodine therapy in postmenopausal patients. Maturitas 2000;35:159-166.

-4 Mora S, Weber G, Marenzi K, Signorini E, Rovelli R, Proverbio MC, Chiumello G: Longitudinal changes of bone density and bone resorption in hyperthyroid girls during treatment. J Bone Miner Res 1999;14:19711977.

5 Cheng S, Xing W, Pourteymoor S, Mohan S: Effects of Thyroxine (T4), 3, 5,3'-triiodo-L-thyronine (T3) and their metabolites on osteoblast differentiation. CalcifTiss Int 2016;99:435-442.

-6 Kanatani M, Sugimoto T, Sowa H, Kobayashi T, Kanzawa M, Chihara K: Thyroid hormone stimulates osteoclast differentiation by a mechanism independent of RANKL-RANK interaction. J Cell Physiol 2004;201:17-25.

7 Harvey L, Arnold B, S Lawrence Z, Paul Matsudaira, David B, James D: Molecular Cell Biology, ed 4 New York, Scientific American Books, 2000. 


\section{Cellular Physiology Cell Physiol Biochem 2018;46:1471-1482 and Biochemistry Published online: April 24, $2018 \quad \begin{aligned} & \text { DOI: 10.1159/000489187 } 2018 \text { The Author(s). Published by S. Karger AG, Basel } \\ & \text { www.karger.com/cpb }\end{aligned}$

Hu et al.: Bone Energy Metabolism and Histomorphometric Changes in Hyperthyroid Rats

8 Dempster DW, Compston JE, Drezner MK, Glorieux FH, Kanis JA, Malluche H, Meunier PJ, Ott SM, Recker RR, Parfitt AM: Standardized nomenclature, symbols, and units for bone histomorphometry: a 2012 update of the report of the ASBMR Histomorphometry Nomenclature Committee. J Bone Miner Res 2013;28:2-17.

-9 Cui L, Li T, Liu Y, Zhou L, Li P, Xu B, Huang L, Chen Y, Liu Y, Tian X, Jee WS, Wu T: Salvianolic acid B prevents bone loss in prednisone-treated rats through stimulation of osteogenesis and bone marrow angiogenesis. PloS One 2012;7:e34647.

10 Lin SE, Huang JP, Wu LZ, Wu T, Cui L: Prevention of osteopenia and dyslipidemia in rats after ovariectomy with combined aspirin and low-dose diethylstilbestrol. Biomed Environ Sci 2013;26:249-257.

11 Cui L, Wu T, Li QN, Lin LS, Liang NC: Preventive effects of ginsenosides on osteopenia of rats induced by ovariectomy. Acta Pharmacol Sin 2001;22:428-434.

12 Zhang J, Li C, Tang X, Lu Q, Sa R, Zhang H: High Concentrations of atmospheric ammonia induce alterations in the hepatic proteome of broilers (Gallus gallus): An iTRAQ-based quantitative proteomic analysis. PLoS One 2015;22:10e0123596.

13 Murphy E, Glüer CC, Reid DM, Felsenberg D, Roux C, Eastell R, Williams GR: Thyroid function within the upper normal range is associated with reduced bone mineral density and an increased risk of nonvertebral fractures in healthy euthyroid postmenopausal women. J Clin Endocrinol Metab 2010;95:3173-3181.

14 Blum MR, Bauer DC, Collet TH, Fink HA, Cappola AR, da Costa BR, Wirth CD, Peeters RP, Åsvold BO, den Elzen WP, Luben RN, Imaizumi M, Bremner AP, Gogakos A, Eastell R, Kearney PM, Strotmeyer ES, Wallace ER, Hoff M, Ceresini G, Rivadeneira F, Uitterlinden AG, Stott DJ, Westendorp RG, Khaw KT, Langhammer A, Ferrucci L, Gussekloo J, Williams GR, Walsh JP, Jüni P, Aujesky D, Rodondi N: Subclinical thyroid dysfunction and fracture risk: a meta-analysis. JAMA 2015;313:2055-2065.

15 Biondi B, Cooper DS: The clinical significance of subclinical thyroid dysfunction. Endocr Rev 2008;29:76131.

16 Vestergaard P, Mosekilde L: Hyperthyroidism, bone mineral, and fracture risk - A meta-analysis. Thyroid 2003;13:585-593.

17 Vestergaard P, Rejnmark L, Weeke J, Mosekilde L: Fracture risk in patients treated for hyperthyroidism. Thyroid 2000;10:341-348.

18 Marshall D, Johnell O, Wedel H: Meta-analysis of how well measures of bone mineral density predict occurrence of osteoporotic fractures. BMJ 1996;312:1254-1259.

19 Ercolano MA, Drnovsek ML, Silva Croome MC, Moos M, Fuentes AM, Viale F, Feldt-Rasmussen U, Gauna AT: Negative correlation between bone mineral density and TSH receptor antibodies in long-term euthyroid postmenopausal women with treated Graves' disease. Thyroid Res 2013;6:11.

20 Lee NK, Sowa H, Hinoi E, Ferron M, Ahn JD, Confavreux C, Dacquin R, Mee PJ, McKee MD, Jung DY, Zhang Z, Kim JK, Mauvais-Jarvis F, Ducy P, Karsenty G: Endocrine regulation of energy metabolism by the skeleton. Cell 2007;130:456-469.

21 Kim JM, Jeong D, Kang HK, Jung SY, Kang SS, Min BM: Osteoclast precursors display dynamic metabolic shifts toward accelerated glucose metabolism at an early stage of RANKL-stimulated osteoclast differentiation. Cell Physiol Biochem 2007;20:935-946.

22 Lemma S, Sboarina M, Porporato PE, Zini N, Sonveaux P, Di Pompo G, Baldini N, Avnet S: Energy metabolism in osteoclast formation and activity. Int J Biochem Cell Biol 2016;79:168-180.

23 Brun J, Berthou F, Trajkovski M, Maechler P, Foti M, Bonnet N: Bone regulates browning and energy metabolism through mature osteoblast / osteocyte PPAR gamma expression. Diabetes 2017; pii: db170116.

$\checkmark 24$ Lee WC, Guntur AR, Long F, Rosen CJ: Energy metabolism of the osteoblast: Implications for osteoporosis. Endocrine Rev 2017;3:255-266.

25 Xiong Q Zhang L, Zhan S, Ge W, Tang P: Investigation of proteome changes in osteoclastogenesis in low serum culture system using quantitative proteomics. Proteome Sci 2016;14:8.

-26 Xiong Q, Zhang L, Xin L, Gao Y, Peng Y, Tang P, Ge W: Proteomic study of different culture medium serum volume fractions on RANKL-dependent RAW264.7 cells differentiating into osteoclasts. Proteome Sci 2015;13:16.

27 Scarlett A, Parsons MP, Hanson PL, Sidhu KK, Milligan TP, Burrin JM: Thyroid hormone stimulation of extracellular signal-regulated kinase and cell proliferation in human osteoblast-like cells is initiated at integrin alphaVbeta3. J Endocrinol 2008;196:509-517.

28 Cheng S, Xing W, Pourteymoor S, Mohan S: Effects of thyroxine (T4), 3, 5,3'-triiodo-L-thyronine (T3) and their metabolites on osteoblast differentiation. Calcif Tissue Int 2016;99:435-442.

29 Gouveia CH, Schultz JJ, Jackson DJ, Williams GR, Brent GA: Thyroid hormone gene targets in ROS 17/2.8 osteoblast-like cells identified by differential display analysis. Thyroid 2002;12:663-671.

30 Ma QM, Dai QT: Tri-iodothyronine induced the bone resorption of osteoclast in rats indirectly. Endocrinol Branch Foreign Med 1992;13:327-331. 